Myongsook S. Oh, Professor, Hongik University

B. S. in Chemical Engineering, UC Berkeley Sc. D. in Chemical Engineering, MIT Lawrence Livermore National Laboratory Texaco, Inc Professor, Department of Chemical Engineering, Hongik University in Korea

Yookyung Bae, Institute for Gender Research in Seoul National University

B.A. in Socioloy at Ewha Womans University in Seoul, Korea M.A. in Socioloy at Ewha Womans University in Seoul, Korea M.A. in Curriculum and Instruction at The University of Texas at Austin Ph.D Candidate in Gender Studies at Seoul National University, Korea 


\section{The effect of group culture on leadership opportunities for female engineering students in Korea}

\section{Introduction}

The importance of leadership training has been prevalent since the 1990's as a part of human resource development in Korea. Industry has heavily invested in training programs, and universities include leadership in the regular curriculum by providing related subjects, as well as by installing leadership centers. Leadership is considered as a core competence for engineers. However, leadership is often pointed out as a quality lacking in female engineers in industry. ${ }^{1}$ One needs to investigate whether female students have a fair share of leadership opportunities as compared to their male counterparts during the college years, and whether they are exposed to environments in which they can develop leadership.

The main prop of Korean society is Confucianism, which values self-cultivation and sociopolitical harmony. Under Confucianism, elders were respected, and a male dominant culture was formed. Even though the influx of western culture is forming new social values and changing organizational cultures, a Confucianism based culture still persists, affecting leadership and organizational culture. The organizational culture of Korean higher education is no different. ${ }^{2}$

Several studies have shown that the age-ranking system and the male dominant culture still carry a heavy weight in Korean universities and create an environment that is disadvantageous to female students. In a Korean study of a coeducational university that had switched from being a women's university, Kim reported that women in coeducational universities are deprived of leadership development opportunities. ${ }^{3}$ She investigated the dynamics of the student body for 4 years after changing to a coeducational system and observed that the ratio of male students in the student body continued to increase after the first year and that women were gradually excluded from leadership positions. Women experienced isolation from the network, and were recognized as a 'woman' rather than a 'leader', while men were presumed to have more qualities of a leader. The excluded women tried to be an exception by taking on male qualities, but they were not successful.

Several studies have shown that women in women's colleges have positive experiences as compared to women in coeducational universities. ${ }^{4-5}$ Students in women's colleges have more contacts with female professors, actively participate in class discussions, and have more opportunities to practice leadership in various academic and non-academic activities. They are also more exposed to women's issues. In other words, female students are in the center of the educational as well as the administrative aspects, leading to high self efficacy and academic achievements. These traits help the graduates to succeed professionally and to maintain self esteem and leadership at a higher level.

The ratio of women in Korean 4-year engineering colleges has been at an $18 \%$ level for the last 10 years, and the ratio of female engineering faculty was about 3.3\% in 2009. Being a minority group in a field known as a men's area, Korean female engineering students are exposed to a 'chilly climate'. ${ }^{6,7} \mathrm{Kim}$ et al. ${ }^{8}$ investigated psychological characteristics of almost 2000 female and male students in 8 universities nation-wide, including the measures for self career aspiration, self efficacy, satisfaction and expectation in engineering careers. 
The results revealed that female students scored significantly lower than male students in all of these variables. In addition, the developmental patterns of female and male students differed significantly; Male student aspiration, self-efficacy, expectation and satisfaction increased with the school experience whereas those of female students did not show any change or decreased.

In addition, the prevailing Confucius culture puts Korean female engineering students into a chillier climate. With mandatory military duty, most male students take their military break after the freshman or sophomore year. When they return to college, they are two or three years older than their female classmates. As an older group under an age-ranking system, male students take it for granted to have a leading role in most activities on campus, depriving leadership opportunities for female students.

In order to develop the leadership competence that industry requires, female students need to make a conscientious effort to develop leadership. In this study, we investigated how students perceive the organization and group culture and how well they are adjusting to it. We also examine leadership opportunities, self evaluation of leadership competence, and the perceived barriers to leadership development.

\section{Methods.}

The survey questions were prepared based on the study by Kim et al. ${ }^{9}$ and Moon et al. ${ }^{10}$ The surveys were conducted during the spring semester, 2010, in a 4-year engineering college, located in Seoul, Korea. About 100 students, from each of 8 majors, participated in the survey, totaling 771 . Of the $771,32.4 \%$ were female $(n=250)$, and $67.7 \%$ were male $(n=521)$.

According to scholastic year, seniors made up the largest fraction, $40.2 \%$, then juniors $31.4 \%$, and sophomores $28.4 \%$. Freshmen were excluded from the survey. Among the male students, $77.4 \%$ completed military service.

The survey questionnaires included vision, self-evaluation of several personal traits and competencies, group or organizational culture, leadership experiences, and mentoring, as listed in Table 1. In this report, we discuss the results from the group culture and leadership experiences. Data processing was performed using the SSPC/PC+ Windows 12.0 program.

\section{Results and Discussion}

\subsection{Group Culture}

In this section, we investigated how students perceive the culture of the group to which they belong, how well they think they are adjusted to the culture, and whether the group culture has a positive effect on leadership development.

The group cultures that students are exposed to in the engineering college were divided into 4 subgroups: department, lectures, experimental and design teams, and student clubs. The culture or the climate of each group was evaluated on a scale of 1 to 5,1 being authoritative and 5 being democratic. Figure 1 shows the results as a function of gender and the completion of military service. Students gave the lowest score for department atmosphere, which was perceived as somewhat authoritative, and the highest score for student clubs, which were perceived as somewhat democratic. Female students consistently gave lower 
Table 1. Structure of questionnaires.

\begin{tabular}{|c|c|}
\hline Variable & \# Questions \\
\hline \hline Vision & 4 \\
\hline Barrier recognition & 1 \\
\hline $\begin{array}{c}\text { Self-evaluation of engineering knowledge, learning ability } \\
\text { extracurricular activities, reputation, self-respect }\end{array}$ & 5 \\
\hline $\begin{array}{c}\text { Recognition of one's strength and weakness \& effort to improve } \\
\text { weakness }\end{array}$ & 1 \\
\hline Crisis management capability & 1 \\
\hline $\begin{array}{c}\text { Organizational culture of department, lectures, experimental and } \\
\text { design teams, and student clubs }\end{array}$ & 4 \\
\hline Adjustment to group culture & 4 \\
\hline Leadership experience & 4 \\
\hline Leadership confidence & 1 \\
\hline Effect of group culture on leadership development & 1 \\
\hline Leadership barriers & 1 \\
\hline Leadership role model & 2 \\
\hline Leadership mentor & 2 \\
\hline
\end{tabular}

scores than males who completed military service, but the difference was not statistically significant. In the case of the students without military experience, they gave even lower scores than female students for all except the student clubs, showing a significant difference with the students completed military service $(\mathrm{F}(1,509) 12.61, \mathrm{p}<0.001)$. The largest difference was seen in the department culture. The male students without military experience seem the most sensitive to the authoritative atmosphere.

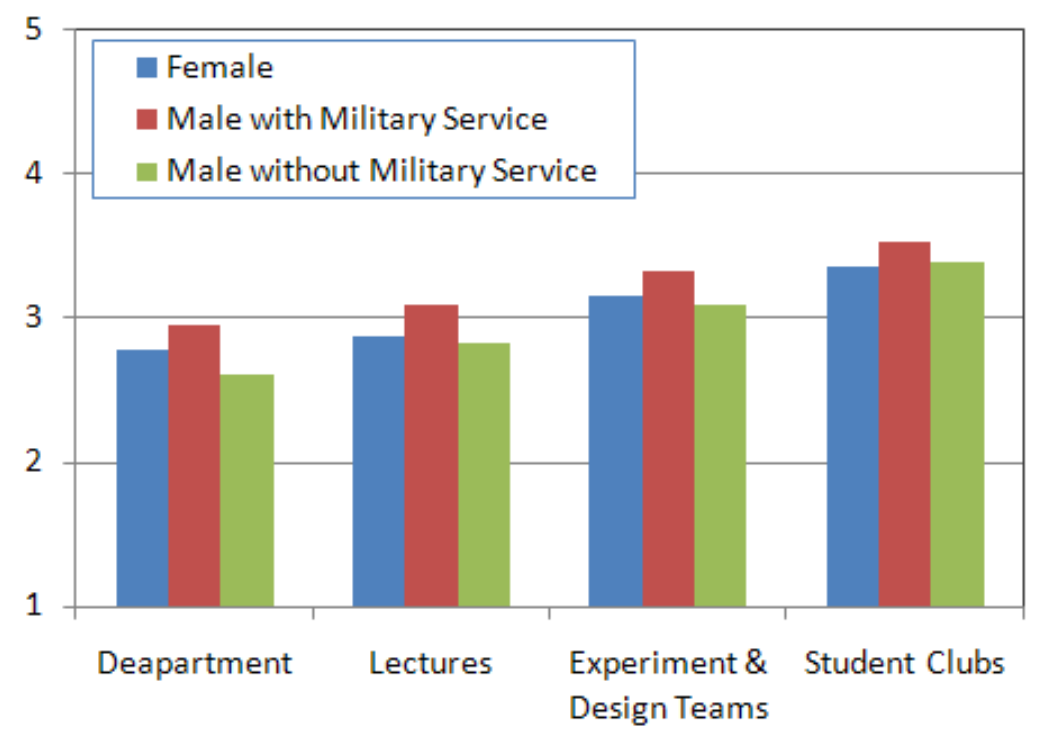

Figure 1. Subgroup culture perceived by students. $(1=$ Authoritative, $5=$ Democratic $)$ 
For the 8 different majors studied, group culture showed distinct differences $(F(1,768)=9.43, p<0.001)$. In the college we investigated, the civil engineering department showed the lowest score of 10.7 (sum of the four subgroups), and the industrial engineering department showed the highest score of 13.7, showing that each department carries its own atmosphere. The department score, however, did not correlate with the female student ratio.

Both male and female students were fairly comfortable with the culture to which they were exposed. The question of how well they were adjusted to the group culture was also on a scale of 5, 1 being "not adjusted at all' and 5 being 'very well adjusted'. $68.9 \%$ of the total students answered positively (average of 3.87 out of 5). Female students gave a lower score of 3.78 than male students $(3.91, \mathrm{p}<0.05)$, but the fraction of students who gave a 1 or 2 was $2.0 \%$, which is less than the $3.5 \%$ of male respondents.

The effect of group culture on leadership development was examined on a scale of 1 to 5 , 1 being 'doesn't help at all' and 5 being 'helps very much'. On this question, the gender and the scholastic year showed statistically significant differences, while the military service did not. The gender difference was compared using the sum of 4 subgroup evaluations. Female students had a lower score of 12.2 versus 13.2 for males $(F(1,768)=21.93, p<0.001)$. Figure 2 shows the changes as the scholastic year increases. The scores of female students increase as the scholastic year increases, while the male students showed the lowest point in the junior year $(F(1,768)=3.69, \mathrm{p}<0.05)$. Even at the lowest point for the male students, the score was higher than the highest point of the female students. Therefore, more of male students and more of upper class female students saw the group culture has the positive effect on the leadership development.

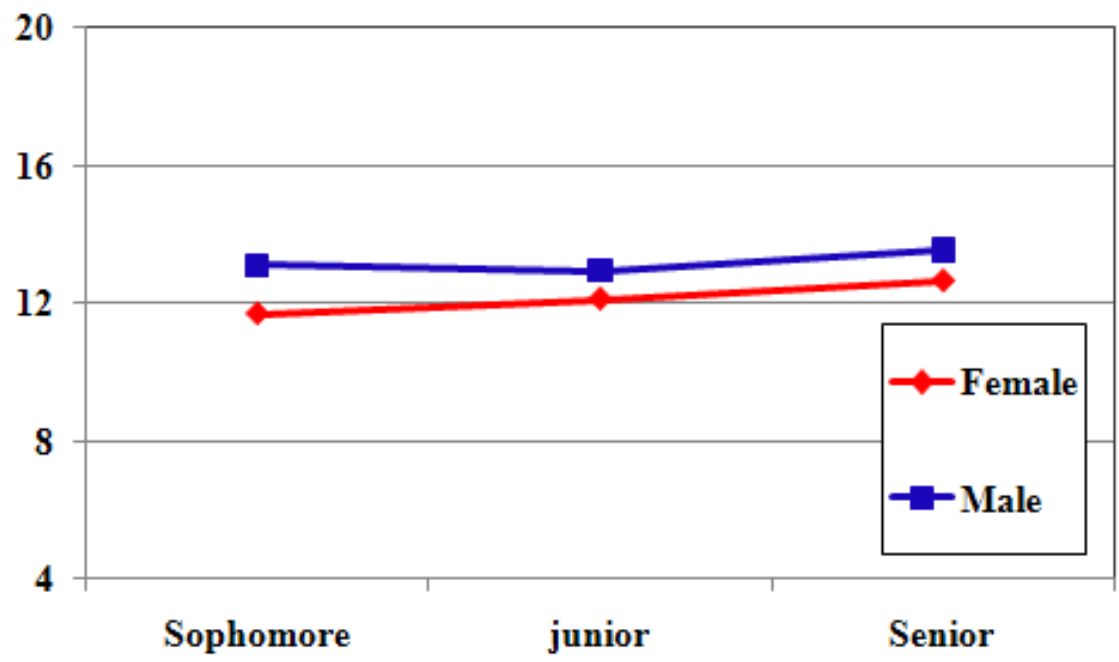

Figure 2. Effect of group culture on leadership development. ( $4=$ Doesn't help at all, 12 $=$ medium, $20=$ Helps very much)

The effect of different group cultures on leadership help show that the department culture and the lectures were at a medium level, 3.07 and 3.01 respectively, while the experimental and design teams and student clubs were more helpful, with a score of 3.40 and 3.51. As shown in Figure 3, the largest difference between the male and female students was in the department culture and the smallest in the experiment and design teams. 


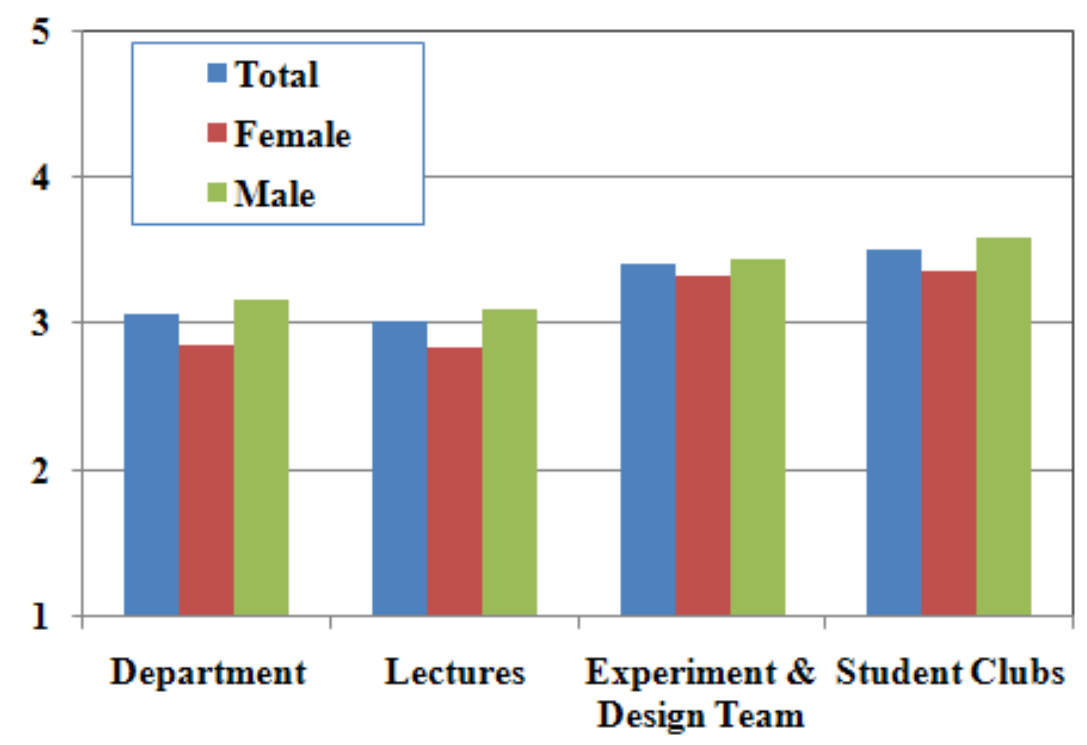

Figure 3. Effect of subgroup culture on leadership development. ( 1 = Doesn't help at all, $3=$ medium, $5=$ Helps very much)

\subsection{Leadership experience}

The leadership experience in various activities during college life was surveyed. The activities were the departmental activities, experiments and designs, student clubs, and offcampus activities. On a scale of 1 to 5, 1 was set as 'none', 2 as ' 1 to 2 times', 3 as ' 3 to 4 times', 4 as 'more than 5 times', and 5 as 'always'. Students, in general, did not have many opportunities to practice and develop leadership. Most students answered 'none' or ' 1 to 2 times'. The departmental activities do not offer many opportunities and $80 \%$ of the students answered 'none' or ' 1 to 2 times'. Even in the other three activities, more than $70 \%$ of the students answered 'none' or ' 1 to 2 times'. Male students had relatively more opportunities than female students $(\mathrm{F}(1,768)=17.45, \mathrm{p}<0.001)$, and the opportunities increased as the scholastic year increased $(F(1,768)=8.68, p<0.001)$, as shown in Figure 4. The largest difference between male and female students was in experiments and designs.

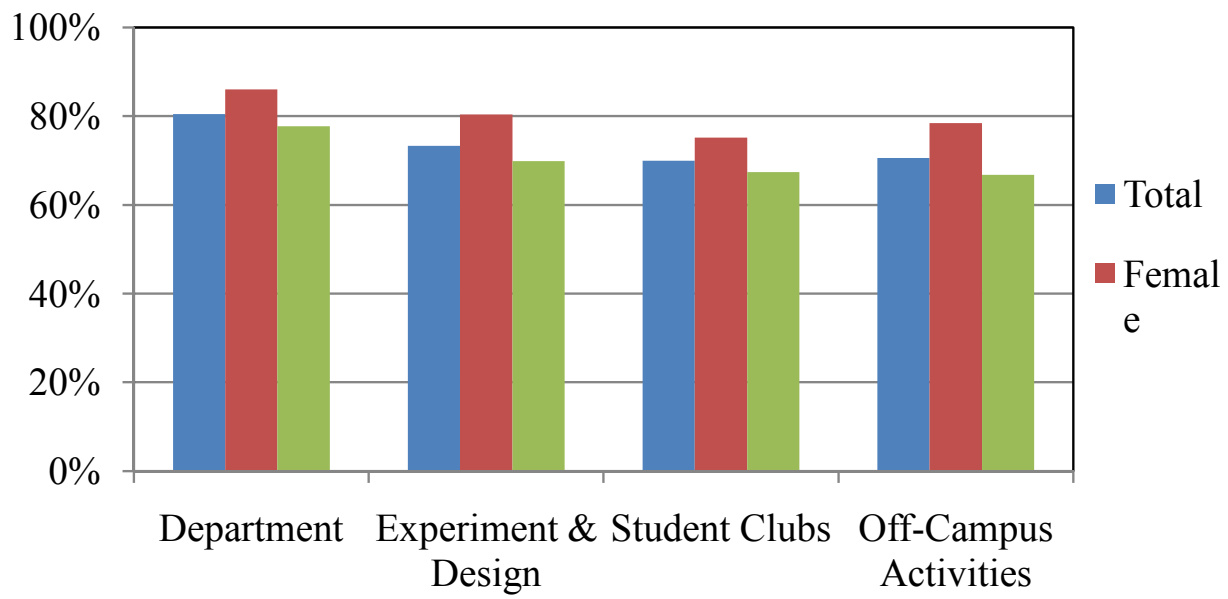

Figure 4. Percentage of students who never had or 1 to 2 times leadership experience in the activities listed. 
Interviews with selected students were conducted regarding the selection of a leader in a design project team. The typical answers were as follows:

'The eldest one is selected as the leader. I am comfortable with that. The age-ranking system is well accepted in society, and it is natural to adopt the same rule in school" - A junior, male

"I was the leader once in a design team. It was a team that consisted of all women of the same age. I have never complained about the eldest being the leader. I am afraid of being a leader. It can be too much to bear." - A senior, female

"I once volunteered to be the leader to get leadership experience. The team accepted it. I am grateful to the elders on the team." - A junior, female

In the design projects in their major subjects, the male students who completed military service naturally got the first opportunity to be a leader because of their age. Furthermore, female students felt a burden and fear to be a leader, and have difficulty volunteering as a leader.

\subsection{Leadership competence}

Leadership competence was examined through confidence in acting as a leader in the four activities discussed above and the self evaluation of leadership competence. Students were fairly confident to be a leader if the opportunities were given to them. On a 5 point scale, with 1 being 'not confident at all' and 5 being 'very confident', students scored 3.36. Students showed the highest score in the student club and off-campus activities, and the lowest level of confidence in departmental activities. Male students showed a higher level of confidence than female students $(\mathrm{F}(1,768)=11.29, \mathrm{p}<0.001)$, as shown in Figure 5(left). The level of confidence increased as the scholastic year increased, but the difference was not statistically significant. The same trends are observed in the self-evaluation of leadership confidence as shown in Figure 5(right). The difference by gender was statistically significant $(F(1,768)=11.00, p<0.001)$, but the difference by the scholastic year was not.
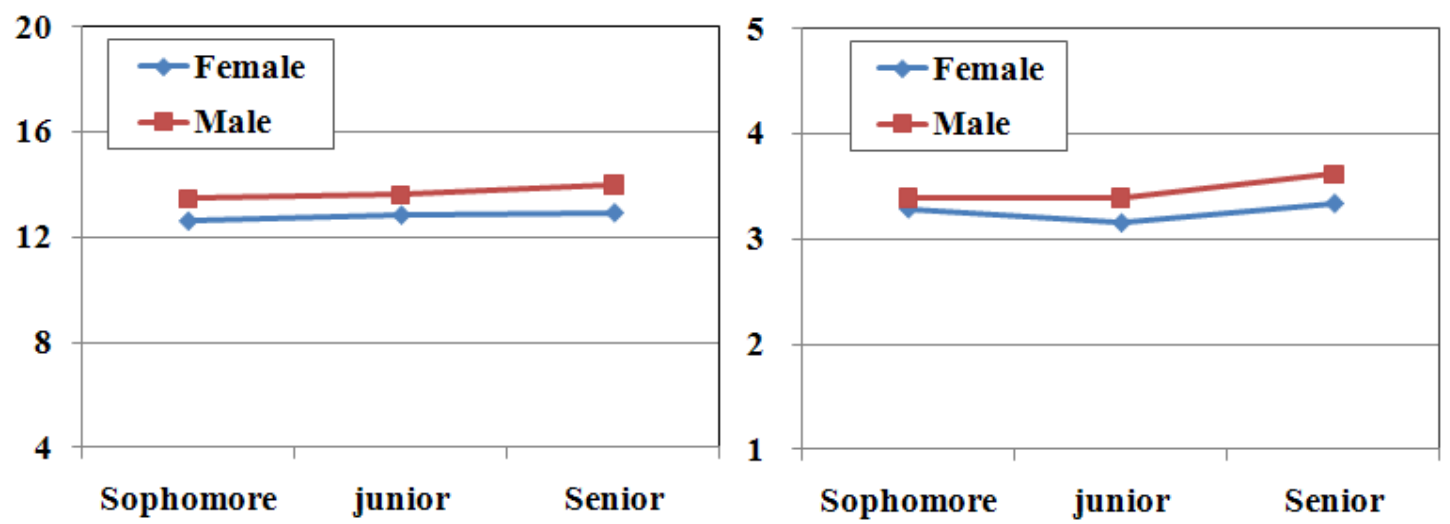

Figure 5. Leader Confidence (left, $4=$ Not confident at all, $12=$ medium, $20=$ Very confident) and self evaluation of leadership competence(right, , $1=$ Insufficient, 3 = medium, $5=$ Outstanding) 


\subsection{The barriers to leadership development}

The male and female student perceived barriers for leadership practice and development were examined. They selected from the following list: 'male dominated culture', 'ranking by age', 'personality', 'lack of self-confidence', 'lack of academic knowledge', 'lack of support from professors', others (write-in). Male students chose 'personality' most frequently, and then 'ranking by age', 'lack of academic knowledge', and 'lack of self-confidence'. The most frequent and the second most frequent did not change with the scholastic year. The sophomore males chose 'lack of confidence' as the $3^{\text {rd }}$ most frequent, while the upperclassmen chose 'lack of academic knowledge', as shown in the right graph of Figure 6. The perceived barriers for female students differed from the male students, and they changed with the scholastic years as shown in the left graph of Figure 6. The sophomore females chose 'personality' most frequently, and then 'ranking by age' and 'male dominated culture'. However, the senior females chose 'male dominated culture' most frequently, 'personality' as the second most frequent, and then 'lack of confidence'. It shows that as the scholastic years accumulated, female students became more aware of the male dominated culture in the organizations they belonged to. In the write-in section, two most frequent answers were 'too troublesome' and 'lack of time'.
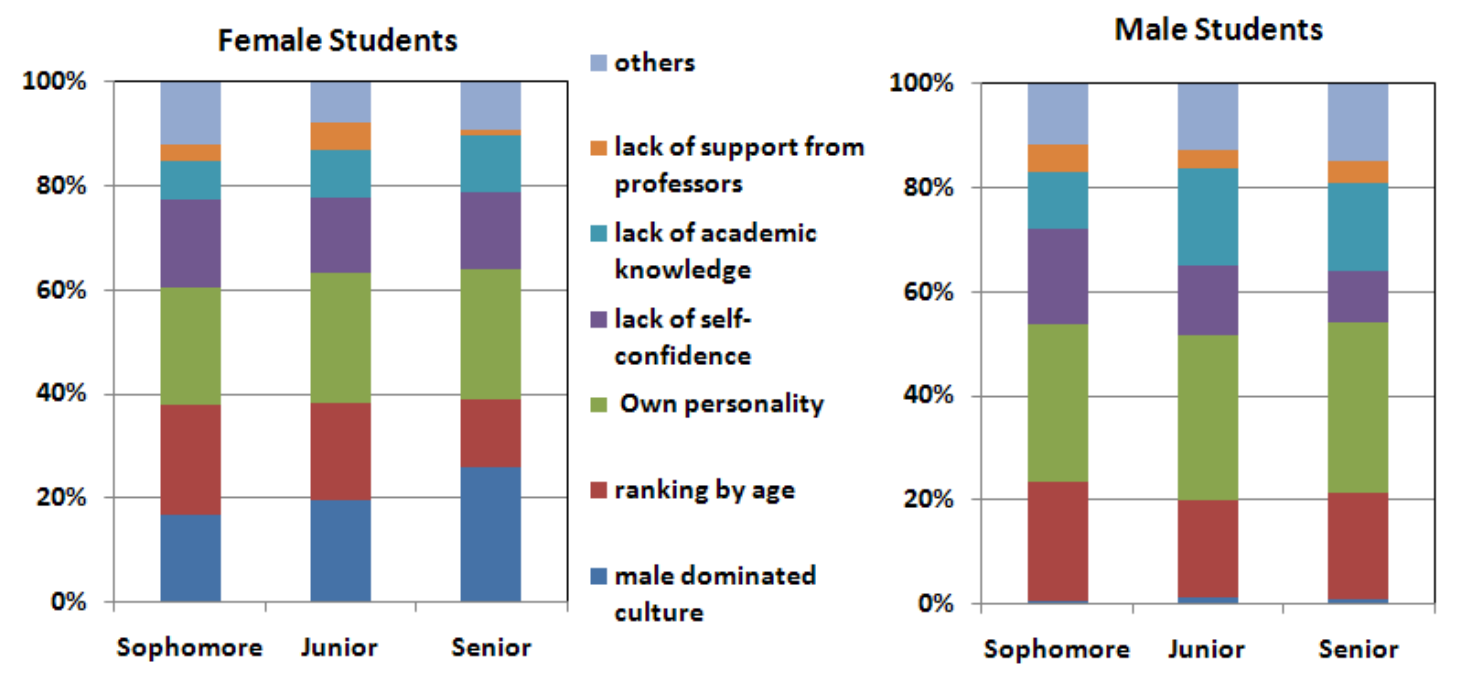

Figure 6. Perceived barriers for the leadership development by female (left) and male (right) students according to scholastic years.

\section{Conclusions}

Most male and female students were fairly comfortable with the culture to which they were exposed. Although female students gave a slightly lower average score, both male and female students thought the group culture was more democratic than authoritative. It should be noted that the group most sensitive to the authoritative environments was not females, but the male students without military service. All students gave fairly high scores to how well they were adjusted to the culture. It turned out that leadership experiences were rather limited for most male and female students, although male students had more opportunities to be the leader. As expected, the leadership competency was higher for male students than females. As to 
leadership barriers, more female students from the junior and senior classes pointed to the male-dominated culture than did the sophomores, while male students attributed it to their personalities.

Despite various studies and indications from the persisting Confucian culture, female engineering students are not very well aware of the disadvantages they are exposed to during the college years. Even though the awareness of a male dominated culture was increased with scholastic years, more female students in senior year thought the group culture had a positive effect on their leadership development. It seems that most female students accept the male dominated and age ranking culture and have little conflict.

Even in western society, women face the problem that men are perceived as leaders and that women need to work harder to prove their leadership competence. Studies also identified 'differential opportunities' for leadership practice as one of the barriers that interfere with recruitment and retention of women leaders ${ }^{11}$ and that limit the self-awareness of women's leadership strength. ${ }^{12}$ In Korean society, the persisting Confucianism makes it more difficult for women in engineering colleges to practice and develop their leadership. With a low awareness level, it is possible that female students do not even make efforts to work on leadership development. Leadership programs specifically for female students should be developed and include methods to raise the awareness of the cultural disadvantages of female students, extra-curricular activities to provide leadership practice opportunities, mentoring, as well as staged leadership training. The role of instructors is important in increasing the leadership opportunities for female students in experiments and design project teams. Instead of leaving the task of selecting leaders to student autonomy, instructors must intervene to give equal opportunities to all students.

The transformation of the culture is a much more challenging task than developing a leadership program. The role of faculties is also very crucial in this, but most faculties are not aware of female student issues or are apathetic to them. Furthermore, the faculties are more comfortable with the prevalent age-ranked, male-dominated culture than the students. The transformation of the culture will not come without serious efforts to raise the faculty awareness on gender issues in engineering education and develop a comprehensive faculty training program. Recruiting more female engineering faculties can also provide a pathway to cultural transformation.

\section{References}

1. Choi, S. J. and Hahn, Y. S. (2005) Data analyses and Policy Suggestions for Training and Utilization of women Engineers, Report to the Ministry of Commerce, Industry, and Energy.

2. Lee, J. L.(2001) "Confucian Thought Affecting Leadership and Organizational Culture of Korean Higher Education," Radical Pedagogy

3. Kim, E. J. (2002), "Study on 'Female Leader' in a university transformed to a Coeducational Institute, An example of Shilla University,” M. A. Thesis, Shilla University

4. Na, Y. K. (2005), "Male-centered Culture of Coeducational Universities Revealed 
through the Voice of Female Students: Based on the Case of Female Students who Experienced both Women's University and Coeducational University," Korean Women's Study, 21(2).

5. Sandler, B.R., Silverberg, L.A., and Roberta M. H. (1996). "The Chilly classroom Climate: A guide to Improve the Education of Women," National Asso. wom. Edu.

6. Sandler, B.R., (1996). "The Chilly Climate," Proc. 1996 WEPAN Nat. Conf., 15-23

7. Sandler, B.R., http://www.bernicesandler.com/id23.htm

8. Jeoung, Y. K, Oh, M. S., and Kim, J. H, (2008). "Examination of Psychological Correlates of Women Engineering Students "J. of Engineering Education Research, 5(4), $34-45$

9. Kim, Y. H. and Kim, H. S., (2000). Comparative Study of Leadership by Male and Female Managers in Corporations, 2000 KWDI Research Report 250-7

10. Moon, M.-K., Kim, H.-Y., and Guem, C.-H., (2009) Studies to Strengthen the CoreCompetency of Female Managerial-ranks in the Public Sector, 2009 KWDI Research Report-15

11. Younkin, W. G, (2009). The Intersection of Discipline and Roles: Dr. Pauline Mack's Story as an Instrumental Case Study with Implications for Leadership in Science, Technology, Engineering, and Mathematics, DoE thesis, Indiana University of Pennsylvania, p72.

12. Lynch, J. M., (2003). Case Studies of Undergraduate Women's Leadership Development at a State University, Ph. D. Thesis, Virginia Polytechnic Institute and State University 